\title{
Local Music Collections: Strategies for Digital Access, Presentation, and Preservation-A Case Study
}

\author{
CAROLYN DOI \\ University Library, University of Saskatchewan, Saskatoon, Saskatchewan, Canada
}

\begin{abstract}
The Saskatchewan Music Collection (SMC) is a local music collection held at the University of Saskatchewan. This case study examines a project to digitize and present this unique special collection in the online environment. The project aims to facilitate access to the collection, preserve the collection and promote scholarship and interest in the music of the province. This article addresses the value of local music collections, as well as challenges and strategies for collection development, copyright issues, promotion and access. An approach for digitizing and presenting the online collection are discussed.
\end{abstract}

KEYWORDS collection management, digitization, university libraries

\section{INTRODUCTION}

This article presents a case study of the Saskatchewan Music Collection (SMC), a special music collection housed at the University of Saskatchewan, which aims to preserve the musical heritage of the province. This local music collection contains unique items of historical significance, many of which are uniquely held in this collection. The collection complements the regular music collections held in the University Library and supports learning and teaching within the University of Saskatchewan Department of Music.

(c) Carolyn Doi

Address correspondence to Carolyn Doi, University Library, University of Saskatchewan, Room 2003, Education Building, 28 Campus Drive, Saskatoon, SK S7N 0X1, Canada. E-mail: carolyn.doi@usask.ca

Color versions of one or more of the figures in the article can be found online at www.tandfonline.com/racl. 
Collecting musical materials, especially those that are rare, historical or unique may present challenges with regard to collection development, cataloguing, storage, and presentation. Nonetheless, the benefits of sharing and preserving such a collection offer numerous benefits for the library and the community at large. Digitization and online presentation of this local music offers new possibilities to expand the research potential of the collection. Not only does this offer an opportunity to digitally preserve fragile or unique items, it is also a gateway to increased awareness, accessibility, and usability of the collection.

\section{COLLECTION HISTORY \& SCOPE}

The SMC was established in 1997 after Neil Richards, a former University of Saskatchewan employee, facilitated its donation to the University Library's Special Collections Unit. Richards had a strong interest in collecting musical artifacts and felt that building the collection would provide opportunities for public engagement, as well as the infrastructure to store and preserve the collection. The collection included historical recordings, scores, and ephemera connected to the provincial by a local composer, artist or theme. The collection is as unique and diverse as the history of Saskatchewan itself, encompassing a wide range of musical styles and tastes. Music is an integral part of the heritage of the community, from the Aboriginal people who have resided here for thousands of years to the settlers who populated the province postconfederation in 1867 (Cottrell) and the current-day artists who continue to shape the local music scene.

In 2001, the SMC was transferred from Special Collections to the University of Saskatchewan Education \& Music Library. This transfer was made in an effort to increase access to the collection, so that students and faculty in the Department of Music, which resides in the same building, may make use of it. The collection was made accessible to the public in an open stacks model, while fragile items were kept in a separate closed-stacks area of the library, and it remains in this configuration to the current day. SMC items do not circulate, but they are available for consultation on site and users may use library media equipment to listen to sound recordings in the library. With the exception of several 8-track and reel-to-reel tapes, the majority of the audio collection is playable using library equipment. The collection has been fully catalogued and remains searchable through the library catalogue, grouped under the series title "Saskatchewan Music Collection."

Managing and growing the collection is an ongoing responsibility of the Music Librarian, who selects new items for the collection from a fund that was established when the SMC moved to the Education \& Music Library. The collection includes nearly 3,000 items in a variety of formats (see Figure 1). The majority of the collection is made up of sound recordings including: 


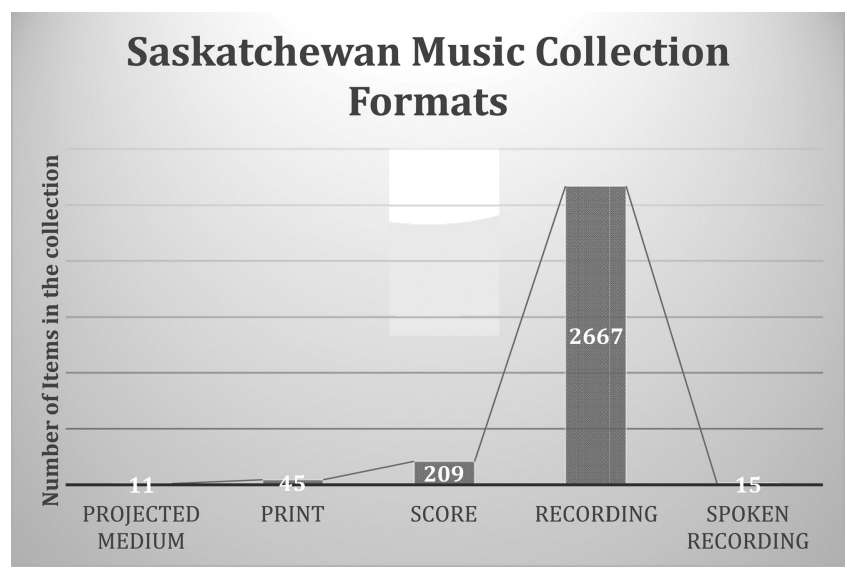

FIGURE 1 Saskatchewan music collection formats.

$45 \mathrm{rpm}$ records, $78 \mathrm{rpm}$ records, 33 1/3 rpm records, 8-track tapes, reel-toreel tapes, cassette tapes, and compact discs. There is a significant selection of historical sheet music collection and works from local composers, which complements the large collection of music scores in the main music collections. Types of ephemera include posters, pamphlets and festival programs. As the collection includes any and all music from the province, a wide variety of musical genres may be found including popular, folk, traditional, jazz and classical music. A standing order with local record label Turtle Island Records has established a significant collection of Aboriginal and Métis music within the SMC. The collection continues to grow as new music is discovered or as historical music are uncovered. Items in the collection date from the early 1900s, when the practice of printing and recording music began to take shape, to the current day (see Figure 2).

The diversity of musical genres offers a fascinating window into the history of the province. Saskatchewan's music during early days of settlement highlights a wide diversity of musical practices including "military and police bands, church choirs, immigrant teachers, enthusiastic residents, and the example of the many travelling groups of instrumentalists and singers who came by rail across the continent" (Swales). Through the SMC, one is able to paint a picture of the history and culture of the province as new communities sprung up and new musical traditions were established. Hudson illustrates the value of music as a cultural artifact and connector in his article "Regions and Place: Music Identity and Place," in which he asserts that "music - in both its production and consumption-can be an important influence in shaping the typically hybrid identities of people and places, of engendering a sense of place and deep attachment to place" (Hudson 633). The music within the SMC has proven to be a valuable resource for local musicians, students and scholars who are interested in learning more about 


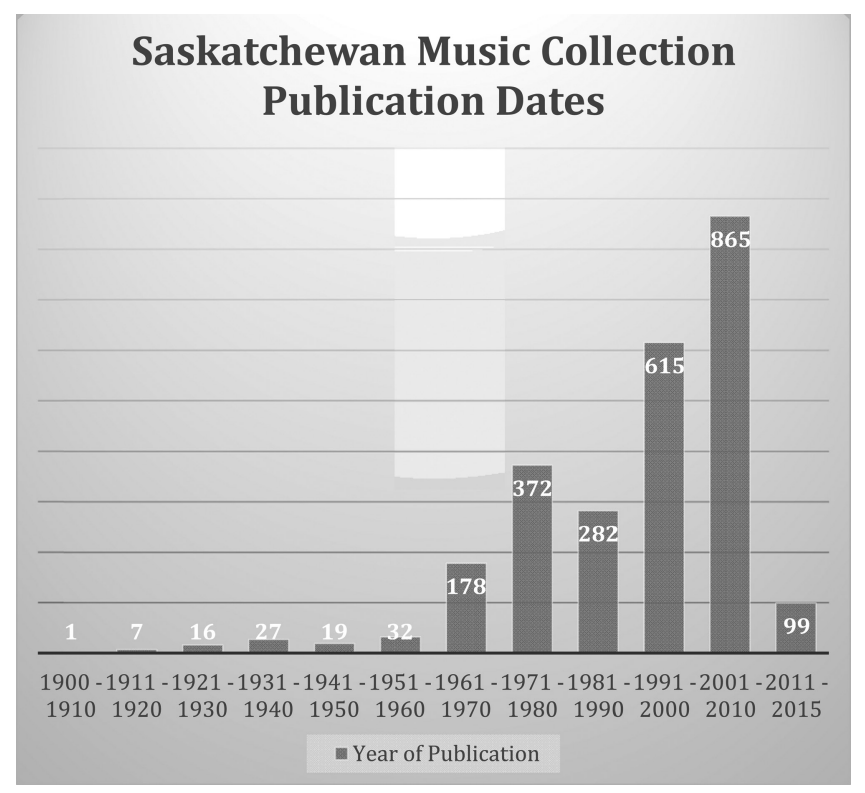

FIGURE 2 Saskatchewan music collection publication dates.

the identity of the province, or to rediscover music that was thought to be missing.

\section{LOCAL MUSIC COLLECTIONS}

The practice of collecting local music is now taking place at many academic and public libraries, and many of these projects are being documented online through digital collections. Some examples include: the Greater Victoria Public Library Local Music Collection, the Toronto Public Library Local Music Collection, the University of Alberta Libraries Edmonton Music Collection and the University of British Columbia Sheet Music Collection. Although the scope of these projects may differ, the collections serve to document local history, preserve items of cultural value and promote the work of the musical community.

The significance and practice of local music collections has not been well documented in the library literature, although it does appear periodically. In his 1940 essay on the topic, titled "The Collection of Musical Material of Local Interest" Spivacke reminds the reader of the impact of such work: "...it should never be forgotten that not only is a service being rendered to a given community but that, at the same time, the librarian so engaged, is preserving for all the country, the documentary evidence of one of the most important elements of our nation's culture" (54). More recently several 
articles and discussions of local music collections have appeared including a special issue of the Canadian Association of Music Libraries Review (vol. 41.1) and a panel discussion at the Music Library Association's 2013 Annual Meeting titled "Local and Regional Music Collections: Issues and Strategies."

Libraries have the capacity to serve as places where local history is preserved and promoted. By building the local collection, the library can help to "ensure that the history their collection presents to future users includes the accomplishments of local musicians, and honestly reflects the local culture in which the library is situated" (Luyk 27). The added value of presenting special collections in the online environment has been widely discussed in recent years as a way to highlight interesting artifacts, promote library collections and engage with users.

\section{COLLECTION DEVELOPMENT}

Collecting local music presents certain challenges to the collections librarian, who must be well aware of the activities and history of the musical community in order to decide how and where to build the collection. Working with special collections is, as Michel suggests, "a guessing game-assisted by knowledge: knowledge of what scholars do and how they do it; knowledge of what interests not only scholars but any thoughtful person; but most of all knowledge of the collections themselves, their content, how they are created, by whom, for whom and for what purpose" (395).

The music librarian also faces another collections challenge related to the changing standards for recording and distributing music. For musicians, it is now much easier to distribute music online as opposed to traditional music stores, which Luyk ascribes to the "low cost and minimal technical knowhow required, and the easy ability to distribute music freely on the internet" (27). As outlined in the 2007 Saskatchewan Music Industry Review, artists are increasingly choosing to distribute recordings through in-person sales at live concerts or in online stores and "the market increasingly demands a digital approach to distribution" (26).

In this environment, it is not enough to rely on traditional library vendors or music stores to purchase music by local musicians. Building the music collection relies on partnerships with members of the community, independent music stores and knowledge of independent music distribution platforms. In cases where an album or musical score may only be available for digital download, the librarian may wish to contact the artist, music label or publisher directly, in order to obtain rights to make a physical library copy or to provide access to the file on a secure library server. Finding out-of-print or rare music materials is possible through second-hand stores, dealers of rare books and online auction sites such as eBay. Building strong relationships with local arts organizations and members of the music community can also 
be an asset and often produces offers of donations for the collection. A good understanding of the music organizations and organizers within local music community, including music record labels, distributors and organizations will be an asset when looking to discover new or emerging artists.

\section{PRESERVATION AND DIGITIZATION}

As many of the items held in the collection are uniquely held at the University of Saskatchewan and the collection is thought to be of interest to the public, a project to digitize the collection was implemented in 2011. The digitization project met two goals: 1) to preserve the collection and 2) to pave the way to build an online, publicly accessible collection. Initially, a sample set of 100 albums was uploaded to the University Library's ContentDM platform, which was used to showcase the library Special Collections at that time. In 2011, the University Library, University of Saskatchewan received funding to develop Saskatchewan History Online, an online aggregate for digital cultural and historical collections from regional galleries, libraries, archives, and museums. Saskatchewan History Online is built on the Islandora framework, an open-source digital asset management software, originally developed at the University of Prince Edward Island's Robertson Library. Currently, Islandora is the preferred platform for the University Library's digital collections, although older collections still reside on ContentDM.

A project charter to move the digitized Saskatchewan Music Collection to the Islandora platform was approved in spring 2013. The project charter outlined the following targets:

1. Continue to digitize recordings and sheet music from the Saskatchewan Music Collection.

2. Create a website for the digital collection, which will allow users to search the collection. The site will also include information about music in Saskatchewan and the history of the collection itself.

3. Update catalogue records in the University Library OPAC to include links to the digitized content

4. Create workflows to train library staff to upload digitized albums to Islandora.

5. Add digitized items from the Saskatchewan Music Collection to the Saskatchewan History Online platform.

Staff has been working to digitize selected sections of the collection since 2011 and over a third of the collection has now been completed. The project began with sound recordings, for which audio, cover images and liner notes are digitized. The audio is digitized using both FLAC and MP3 formats, while images are digitized using TIFF and JPEG. Higher resolution 
files are made for preservation purposes and stored on a library server, while lower quality formats are used for quick retrieval in the online environment. In keeping with intellectual property and copyright restrictions, each track is streamed for 30 seconds at a time. Items that are in the public domain, or for which the library has acquired copyright clearance can be accessed in their entirety.

The progression of the website and migration of the collection onto Islandora required a partnership among key partners within the University Library, including members Library IT, Cataloguing, Digitization, the Music Librarian, and library staff. Work on the SMC website began in late 2014 and was launched in January 2015, to coincide with a local music exhibition held at the University Library from January to March 2015. The site contains several search features including simple keyword search, advanced search and a browsable list. Information about the history of the collection, featured content, and a bibliography of related resources is also available. The digitized objects from the collection are described in detail using MARC metadata, which can be found within the Library Catalogue. Crosswalks have been established to present the collection in Islandora using the Metadata Object Description Schema (MODS).

Once the digitized files were added to Islandora, they were also made searchable through the Saskatchewan History Online platform, broadening visibility of the collection again. The SMC website was launched in conjunction with an exhibition titled "Music in Saskatchewan," which was displayed in the Link Gallery at the University of Saskatchewan Murray Library in January 2015. The exhibition included items from the Saskatchewan Music Collection, Special Collections \& Archives and Library Collections; all related to the music of the province and was accompanied by a guided listening tour of the exhibition materials, featuring digitized content from the Saskatchewan Music Collection.

The remaining aspects of the project are planned for completed in spring 2015, including training to staff to upload content to Islandora and adding links to the catalogue records, such that the digitized content is accessible by searching the library catalogue.

\section{CONCLUSIONS}

The goal of presenting the Saskatchewan Music Collection online is a useful step toward increasing knowledge of local music history and building the music community itself. As Wasner states, "it seems clear that we must not only help our collections speak to the needs of our communities, but to use our collections to help build community. Our access points and our technologies should allow members of the library community to converse with each other and in their own minds, with artifacts that house ideas, 
expressions, and emotions from all times and places" (333). Music in Saskatchewan has been experienced far more than it has been written about, so the online collection serves to uncover the rich and vibrant musical history of the province.

Digitizing the collection greatly increases the accessibility of the collection for all patrons and is supports internal library recommendations that the library continue to mainstream the creation and use of digital resources. Presenting the SMC online allows for increased visibility of the collection within the community, while removing barriers to access. The website provides library patrons with a user-centered experience that parallels the increased availability of digital music collections elsewhere on the web. Positioning the digitized collection within Saskatchewan History Online is ideal, as the SMC remains the most comprehensive collection of historical musical documents within the province.

\section{REFERENCES}

Hudson, Ray. "Regions and Place: Music Identity and Place." Progress in Human Geography 30.2 (2006): 626-34. Web. 12 Dec. 2014.

Luyk, Sean. "Scene but not Heard: Collecting Local Music." CAML Review 41.1 (2013): 22-33. Web. 10 Dec. 2014.

Peter Michel, (2005) "Digitizing Special Collections: To Boldly Go Where We've Been Before." Library Hi Tech 23.3: 379-95.

Spivacke, Harold. "The Collection of Musical Material of Local Interest." Notes 8 (1940): 49-54. Print.

Swales, Robin. "Music." Encyclopedia of Saskatchewan. Regina: Canadian Plains Research Centre, 2005. Print.

Wasner, Jeff. "Collecting and Collaborating to Build Community: The Evolution of a Local Music Collection at a Small Liberal Arts College Library." Technical Services Quarterly 31.4 (2014): 332-57. Web. 11 Dec. 2014. 